\title{
PENGAJARAN MENULIS TEKS TANGGAPAN MELALUI APLIKASI ZOOM-MEETING DAN WHATSAPP GRUP: SEBUAH PENELITIAN PERBANDINGAN
}

\section{TEACHING WRITING RESPONSE TEXT THROUGH ZOOM MEETING APPLICATION AND WHATSAPP GROUPS: A COMPARATION STUDY}

\author{
SITI ISTIQOMAH \\ SMPN 263 Jakarta
}

\begin{abstract}
This study aims to reveal and report the impact of using the zoom-meeting platform compared to the WhatsApp group application in teaching and learning writing of reported texts for SMPN students in Jakarta. The participants of this research were students of class IX SMPN in Jakarta. This research is a mixed-method method with a comparative study design. The research participants were divided into two groups, namely zoom-meeting and WhatsApp group classes. The instruments were test and non test. The data collection procedure was carried out before the implementation of learning, during learning, and post-learning. The results of the study show that the students' writing ability in the first cycle, both of Zoom-meeting group is 79.69 and WhatsApp group class is 77.88. In the second cycle, the Zoom-meeting group is 79.8 and WhatsApp group is 76.63. Meanwhile, in the 3rd cycle, the result of the Zoom-meeting group is 79.71 and WhatsApp group is 76.85. Furthermore, the students' score of writting the response text both in the Zoommeeting class was 83.00 and the WhatsApp group is 70.63 , there was a $12.37 \%$ difference between the WhatsApp group and Zoom-meeting group. It can be drawn the conclusion that the use of the Zoom-meeting application and WhatsApp can improve the students 'ability to write response text for senior high school level.
\end{abstract}

\begin{abstract}
Abstrak.
Penelitian ini bertujuan untuk mengetahui dan melaporkan dampak penggunaan platform Zoommeeting dibandingkan dengan aplikasi grup WhatsApp dalam pembelajaran menulis teks laporan siswa SMPN di Jakarta. Partisipan dalam penelitian ini adalah siswa kelas IX SMPN di Jakarta, dilaksanakan mulai Januari sampai dengan April tahun 2021 secara daring online. Penelitian ini merupakan metode campuran dengan desain studi banding dengan 3 siklus. Partisipan penelitian dibagi menjadi dua kelompok, yaitu kelas Zoom-meeting dan grup WhatsApp. Instrumen yang digunakan adalah tes dan nontes. Pengumpulan data dilakukan dengan teknik sampel purposive sampling technique dan dilakukan sebelum pelaksanaan pembelajaran, pertengahan pembelajaran, dan pasca pembelajaran. Hasil penelitian menunjukkan bahwa kemampuan menulis siswa pada siklus 1, kedua kelompok Zoom meeting adalah 79,69 dan kelompok WhatsApp adalah 77,88. Selanjutnya pada siklus kedua, grup Zoom-meeting adalah 79,8 dan grup WhatsApp adalah 76,63. Sedangkan pada siklus 3, hasil grup Zoom-meeting adalah 79,71 dan grup WhatsApp 76,85. Selanjutnya, skor siswa menulis teks respon baik di kelas Zoom-meeting adalah 83,00 dan grup WhatsApp adalah 70,63, ada perbedaan 12,37\% antara grup WhatsApp dan grup Zoommeeting. Dapat ditarik kesimpulan bahwa penggunaan aplikasi Zoom-meeting dan WhatsApp dapat meningkatkan kemampuan siswa dalam menu/is teks tanggapan untuk tingkat SMA.
\end{abstract}

\begin{tabular}{cl}
$\begin{array}{c}\text { Keywords: } \\
\text { Kata kunci: }\end{array}$ & $\begin{array}{l}\text { Writting, ResponseText, Zoom-meeting, WhatsApp Group } \\
\text { Menulis, Teks Tanggapan, Zoom-meeting, WhatsApp }\end{array}$ \\
\hline$\left(^{\star}\right)$ Corresponding Author: & istisahid@gmail.com \\
\hline How to Cite: Istiqomsah, S. (2021). Pengajaran Menulis Teks Tanggapan Melalui Aplikasi Zoom-Meeting dan Whatsapp Grup: \\
Sebuah Penelitian Perbandingan. Jurnal Lingkar Mutu Pendidikan, 18 (1), 107-113. https://doi.org/10.54124/ilmp.v18i1.15 \\
\hline
\end{tabular}

\section{PENDAHULUAN}

Pembelajaran di masa pandemi Covid 19 memaksa setiap pelaku pendidikan mengubah pola pelaksanaan pembelajaran. Pembelajaran yang sedianya dilaksanakan dengan tatap muka; mendidik, melatih, membimbing memberikan materi, membina kepribadian, secara langsung dan bersentuhan antar pendidik dan peserta didik, kini pendidik harus melakukan pembelajaran, menyampaikan 
materi, dan seluruh pembimbingan secara daring/online. Hal ini memaksa para pendidik serta peserta didik untuk intens dengan komputer, handphone, tablet ataupun gawai (gadget). Memahami program, aplikasi, ataupun konten yang terdapat di dalam Handphone atau komputer merupakan aspek yang penting. Karena melalui aneka media berupa handphone, tablet atau komputer inilah kita dapat mengakses materi, konten pembelajaran sehingga pembelajaran dapat berlangsung secara daring (e-learning).

Selama pembelajaran jarak jauh (PJJ) munculnya berbagai masalah atau kendala menuntut guru untuk mampu mandiri, menyusun dan menyelenggarakan ujian secara online. Hal ini memaksa guru untuk belajar IT agar mampu menyelenggarakan pembelajaran dan penilaian. Siswa menggunakan smart-phone atau laptop untuk belajar. Guru harus mampu mempersiapkan dan menyampaikan materi pelajaran dalam bentuk digital. Strategi pembelajaran yang dilakukan dengan menggunakan whatsapp grup atau google classroom kurang efektif karena jawaban atas setiap tugas bisa saja sama dengan tugas yang dikirimkan ternan sebelumnya, disamping itu, hal tersebut menyebabkan berita yang masuk ke dalam handphone gurunya semakin banyak membuat proses keluar masuknya informasi menjadi terhambat. Penggunaan media pembelajaran yang lain google classroom cukup membantu baik guru maupun peserta didik, karena adanya pembatasan waktu yang ditentukan guru agar tugas tersebut segera dikerjakan dan ada kolom nilai dan pemberian komentar. Untuk itu peserta didik harus meng-uploud tugas-tugas mereka ke google classroom. Tentu saja kebutuhan kuota lebih besar dari pada whats app.

Berdasarkan alasan tersebut dilaksanakan penelitian perbandingan antar pembelajaran dengan media Whatsapp dengan pembelajaran menggunakan media Zoom-meeting dalam upaya untuk mengetahui ada tidaknya perubahan yang lebih baik setelah diterapkan teknik -teknik mengajar dengan bantuan aplikasi digital. Tampilan materi ajar dalam bentuk power point yang juga diubah menjadi lebih baik dan menarik untuk dicermati peserta didik.

Menulis dapat merupakan kegiatan mengemukakan pendapat, ide, atau gagasan dalam bentuk lambang bahasa tulis agar dapat dibaca orang lain. Kemampuan menulis juga mengasah kamampuan untuk meningkatkan pengaturan dan pengorganisasian (Mahsun 2018). Sedangkan teks tanggapan merupakan wacana berisi gagasan atau ide yang disampaikan individu mengenai problematika yang sedang dihadapi (Asep Ganda Sadikin 2019).

Zoom berupa sebuah aplikasi buatan Amerika yang menyediakan layanan video telephony dan chaton line melalui platform perangkat lunak (Ciaudya 2020). Sebagaimana tulisan Bunga Cintya Claudya, mahasiswa Pendidikan Sosiologi FIS UNJ di www.kopasiana.com menyampaikan data terdapat 2,22 pengguna zoom-meeting, karena keunggulan dari aplikasi zoom-meeting dibandingkan dengan aplikasi video conference lainnya. Penyajian pembelajaran menjadi lebih luas seolah tanpa batas ruang dan waktu sebagaimana pembelajaran kelas.

Putri Zakiyatul Zannah, dan lain-lain dalam sebuah artikel di Jurnal Pendidikan www.medianeliti.com berjudulPenggunaan Media Pembelajaran Zooming Presentation untuk meningkatkan hasil belajar peserta didik kelas X pada Konsep Suhu dan Kalor di SMA Negeri di Tangerang Selatan melaporkan bahwa rata-rata hasil belajar responden yang menggunakan media Zoom presentation lebih tinggi dibandingkan responden yang tidak menggunakan media Zoom Presentation, yaitu 77,57 berbanding 68,00 (Putri Zakiyyatul Zannah 2014). Hasil belajar peserta didik di kelas Zoom-presentation lebih unggul dalam meningkatkan kompetensi mengingat (C1), memahami (C2), menerapkan (C3), dan menganalisis (C4).

Saat pembelajaran tatap muka, guru masih menjumpai masalah yaitu rendahnya hasil belajar bahasa Indonesia materi teks tanggapan karena kurangnya pemahaman konsep tentang aspekaspek menulis teks tanggapan. Masa pandemi, pembelajaran dilakukan dari rumah (BDR) dimana permasalahan semakin nyata, menggunakan Whastapp saja tidak cukup. Pertemuan tidak terjadi, diskusi, interaksi semakin terbatas, penggunaan media-media elektronik pembelajaran seperti Whatsapp grup, Google classroom, Zoom-meeting menjadi suatu pilihan.

Untuk menjawab asumsi dan menjadi tujuan penelitian diharapkan akan memiliki dampak pada peningkatan kompetensi maupun peningkatan kreativitas guru dan peserta didik dalam belajar menggunakan berbagai platform dan strategi pengajaran dan pembelajaran sehingga memberi kontribusi terhadap perkembangan peserta didik dalam aspek kompetensi berupa meningkatnya kemampuan menulistekstanggapan. 


\section{METODE PENELITIAN}

Penelitian ini menggunakan metode gabungan antara kuantitatif dan kualitatif deskriptif dengan desain tindakan komparatif, dalam hal ini membandingkan dua media atau aplikasi teknologi pembelajaran online untuk proses kegiatan belajar dan mengajar. Kegiatan ini berupaya mengetahui dan menjelaskan ada tidaknya dampak penerapan media ini terhadap hasil pembelajaran dalam kondisi yang terkendalikan (Sugiyono 2010:107). Penelitian ini dilaksanakan mulai Januari sampai dengan April tahun 2021 secara daring online.

Partisipan penelitian ini adalah peserta didik kelas IX pada sebuah SMP Negeri di Jakarta. Pemilihan sampel dilakukan dengan teknik sampel bertujuan (purposive sampling technique). Alasan pengambilan sampel atas dasar pertimbangan ketersediaan dan kesesuaian dengan karakteristik dan kondisi pada saat penelitian berlangsung.

Partisipan dalam penelitian ini dibagi ke dalam dua kelompok; satu kelompok melaksanakan pembelajaran menggunakan media Zoom-meeting, sementara kelompok lainnya menggunakan media WhatsApp aplikasi. Pelaksanaan pembelajaran dilakukan selama tiga kali pertemuan, kegiatan ini bertujuan melihat tingkat kemajuan dan kemampuan menyerap materi ajar dengan penggunaan media Zoom-meeting dalam pembelajaran menulis teks tanggapan. Prosedur penelitian ini dapat dibuat dalam bentuk bagan.

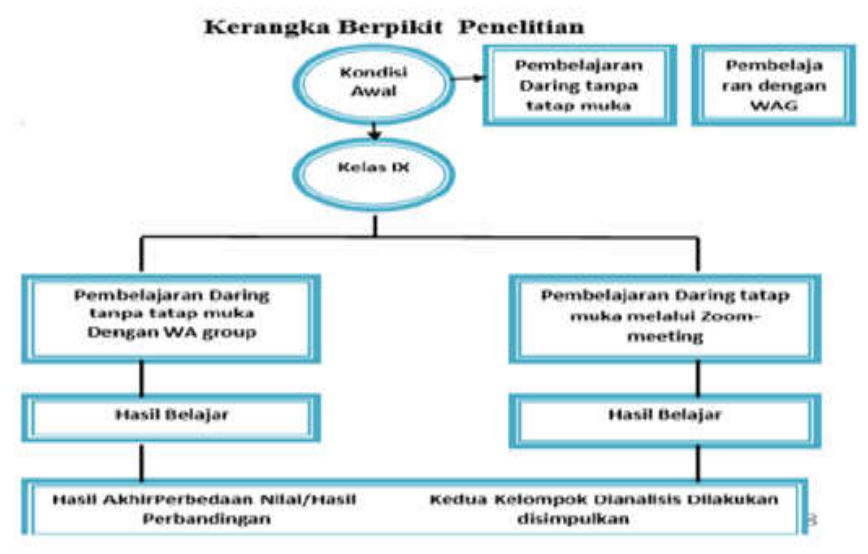

Gambar 1.1 Skema Kerangka Berpikir Penelitian

Prosedur pengumpulan data dalam penelitian ini melalui pemberian tes tertulis dan angket. Kedua jenis tes ini disampaikan melalui Google Form. Pengamatan selama pelaksanaan pembelajaran Zoom dan tes akhir dilakukan untuk mengetahui tingkat keberhasilan belajar peserta didik dari aspek pengetahuan (cognitive aspect).

Prosedur analisis data dalam penelitian ini, khususnya berkenaan dengan data dalam bentuk angka, seperti hasil tes akhir dianalisis secara kuantitatif, bertujuan mengetahui ada tidaknya perubahan capaian atau hasil belajar peserta didik yang diajar dengan menggunakan media Zoom meeting dibandingkan dengan hasil tes akhir peserta didik yang melaksanakan pembelajaran menggunakan media Whatsapp. Data-data dari angket diinterpretasikan dari angka dan grafik menjadi tafsiran yang memberi makna secara kualitatif.

Demikian pula instrumen kegiatan belajar peserta didik dianalisis secara kualitatif. Semua data yang diperoleh digunakan untuk menjawab hipotesis penelitian yang dilakukan.

Proses pelaksanaan penelitian ini sebagai berikut. Pertama tahap pra-eksperimen, yaitu menentukan sampel dari populasi, tahap persiapan rencana pelaksanaan pembelajaran (RPP) sesuai sintak, sumber, bahan, menyusun power point pembelajaran. Menyusun Instrumen penugasan, lembar kerja peserta didik, menyiapkan lembar observasi untuk mencatat aktivitas peserta didik.

Tahap tindakan eksperimen: pelaksanaan penelitian berlangsung dalam pertemuan I, II, dan III. Pelaksanaan pembelajaran dengan materi sama, untuk kelas Zoom-meeting dan kelas Whatsapp. Setiap pertemuan diawali dengan pendahuluan, kegiatan inti, penutup, dan diakhiri dengan penugasan dan disertai tes akhir (tes pengetahuan) untuk pertemuan ketiga. 
Tahap observasi dilakukan dengan mencatat aktivitas peserta didik selama pelaksanaan eksperimen berlangsung yang dituangkan dalam catatan lapangan, disertai dengan dokumentasi kegiatan. Pengamatan berkisar kehadiran, keaktifan peserta didik dalam kelas zoom, keaktifan merespon pertanyaan maupun ketepatan dalam pengiriman tugas.

Tahap pengambilan data: sebagai data pertama adalah wawancara tertulis tentang pembelajaran bahasa Indonesia yang telah berlangsung, pengenalan peserta didik tentang materi teks tanggapan, Berikutnya adalah data observasi langsung maupun tidak langsung yang dilakukan selama pembelajaran Zoom-meeting dan pembelajaran Whatsapp grup di rumah.

Data penilaian tugas setiap pertemuan dan data akhir pelaksanaan tes pengetahuan Bab IV, teks tanggapan serta angket. Seluruh data untuk menjawab seberapa efektif penggunaan media zoommeeting ini dalam peningkatan kemampuan menulistekstanggapan.

\section{HASIL DAN PEMBAHASAN}

Penelitian ini berupaya menjawab masalah dan hipotesis yang disampaikan sebelumnya. Data nilai yang dikumpulkan berupa data nilai penugasan pertemuan I mengenai identifikasi dan menyimpulkan informasi teks tanggapan yang disebut (P1). Kemudian data nilai penugasan pertemuan II tentang telaah struktur dan kebahasaan teks tanggapan disebut (P2). Serta data nilai penugasan pertemuan III tes esai menulis teks tanggapan (P3). Nilai evaluasi akhir Bab IV adalah (E) berbentuk pilihan ganda disampaikan melalui google form. Tes ini dilakukan setelah pertemuan ketiga dengan waktu pengerjaan satu jam, dan diulang kembali satu jam untuk memberi waktu siswa yang berhalangan karena suatu hal. Semua informasi disampaikan lengkap melalui Whatsapp group.

Penilai penugasan pertemuan I rata-rata nilai kelas dengan media zoom-meeting 79,69 , sementara kelas dengan media Whatsapp 77,88. Penugasan pertemuan II rata-rata nilai kelas Zoom-meeting 79,81 sementara kelas Whatsapp 76,63. Penilaian penugasan pertemuan III rata-rata perolehan nilai kelas Zoom-meeting 79,71 sementara kelas Whatsapp 76,85. Penilaian akhir kelas eksperimen memperoleh rata-rata nilai 83,00 sementara kelas kontrol 70,63. Penilaian P1, P2, dan P3 hasilnya tidak tampak perbedaan yang mencolok perbedaan hasil pembelajaran siswa melalui pengumpulan nilai penugasan. Namun kelas dengan Zoom-meeting tetap memiliki nilai yang lebih besar dan kualitas tugas yang lebih baik. Hal tersebut dimungkinkan karena peserta didik memiliki waktu pengerjaan yang lebih lama yaitu satu minggu lebih sehingga banyak kesempatan untuk mencari tahu jawaban melalui bertanya ternan yang mengumpulkan tugas terlebih dahulu. Pembelajaran menggunakan media zoom-meeting partisipan memiliki kompetensi yang lebih tinggi dalam setiap pertemuan 1,11,111, artinya penggunaan media ini lebih efektif meningkatkan nilai hasil belajar dibandingkan dengan pembelajaran menggunakan media Whatsapp saja. Berikut adalah tabel perbedaan atau selisih perolehan nilai antar kelas eksperimen dan kelas kontrol.

Tabel 1 Perbandingan Nilai Kelas Eksperimen dan Kelas Kontrol

\begin{tabular}{lllll}
\hline & P1 & P2 & P3 & E \\
\hline Kelas Eksperimen & 79,69 & 79,81 & 79,71 & 83,00 \\
Kelas Kontrol & 77,88 & 76,63 & 76,85 & 70,63 \\
\hline Persentase Perbedaan Nilai & $1,81 \%$ & $3,18 \%$ & $2,86 \%$ & $12,37 \%$ \\
\hline
\end{tabular}

Dalam tabel dijelaskan bahwa perbedaan nilai penugasan tidak signifikan antara kelas Zoommeeting dan kelas Whatsapp. Namun pada nilai evaluasi akhir Bab IV pengetahuan teks tanggapan tampak perbedaan yang signifikan mencapai $12,37 \%$.

Artinya selama pembelajaran daring peserta didik dapat membelajarkan dirinya secara mandiri. Namun pemahaman dan penguasaan materi secara mendalam akan dapat dicapai apabila pembelajaran dilakukan dengan tatap muka walaupum secara daring on-line. Menggunakan Zoommeeting. Data hasil pengamatan selama pembelajaran zoom berlangsung dapat disampaikan rekap data sebagai berikut: 
Tabel 2. Data Hasil observasi dalam Pembelajaran Materi Menulis Teks Tanggapan

\begin{tabular}{|c|c|c|c|c|}
\hline Pertemuan & Menutup Video & Antusias & Aktif & Bertanggung jawab \\
\hline I & 8 & 7 & 4 & 11 \\
\hline ॥ & 5 & 7 & 4 & 13 \\
\hline III & 3 & 7 & 6 & 16 \\
\hline \multicolumn{5}{|c|}{ Kelas WhatsApp } \\
\hline Pertemuan & Menutup Video & Antusias & Aktif & Bertanggung jawab \\
\hline I & 4 & 6 & 3 & 8 \\
\hline II & 4 & 6 & 3 & 8 \\
\hline III & 6 & 6 & 3 & 8 \\
\hline
\end{tabular}

Observasi yang dilakukan selama pelaksanaan pembelajaran menulis teks tanggapan berlangsung tiga kali pertemuan, data menyampaikan bahwa pembelajaran kelas Zoom-meeting menuntut peserta didik lebih siap, memiliki antusias yang lebih tinggi, keaktifan yang meningkat, dan tanggung jawab yang mencapai $100 \%$ melesaikan tugas pembelajaran sesuai waktu yang ditentukan. Sedangkan kelas Whatsapp memiliki kecenderungan stagnan artinya responden yang yang antusias, aktif, dan yang bertanggung jawab menyelesaikan tugas sesuai waktu pelaksanaan adalah responden yang sama, tidak mengalami peningkatan.

Data pendukung terkait penelitian ini antara hasil angket mengenai pendapat peserta didik dalam pelaksanaan pembelajaran baik kelompok eksperimen yang menggunakan media Zoom-meeting maupun kelompok kontrol yang menggunakan media WhatsApp biasa. Hasil angket yang yang disampaikan melalui Google Form tersebut antara lain sebagai berikut:

Tabel 3. Kisi-kisiangket

\begin{tabular}{|c|c|c|c|c|}
\hline NO & INSTRUMEN & OPTION & & PERSENTASE \\
\hline 1. & $\begin{array}{l}\text { Perasaan Peserta didik terkait sulit tidaknya materi menulis } \\
\text { teks tanggapan }\end{array}$ & $\begin{array}{l}\text { Mudah } \\
\text { Sangat muda } \\
\text { Sulit }\end{array}$ & $\begin{array}{r}=5 \\
=1 \\
=10\end{array}$ & $\begin{array}{l}33,33 \% \\
06,26 \% \\
62,50 \%\end{array}$ \\
\hline 2. & Pendapat peserta didik terkait letak kesulitannya & $\begin{array}{l}\text { Deskripsi } \\
\text { Struktur } \\
\text { Kebahasaan } \\
\text { Penilaian }\end{array}$ & $\begin{array}{l}=5 \\
=1 \\
=3 \\
=7\end{array}$ & $\begin{array}{l}33,33 \% \\
06,26 \% \\
18,75 \% \\
43,75 \%\end{array}$ \\
\hline 3. & $\begin{array}{l}\text { Pendapat pesertadidikselama } \\
\text { pembelajaran dengan WAG. }\end{array}$ & $\begin{array}{l}\text { Mudah } \\
\text { Sulit }\end{array}$ & $\begin{array}{l}=10 \\
=6\end{array}$ & $\begin{array}{l}62,50 \% \\
37,50 \%\end{array}$ \\
\hline 4. & $\begin{array}{l}\text { Pendapat pesserta didik terkait perlu pembelajaran } \\
\text { menggunakan media, metode, teknik khusus. }\end{array}$ & $\begin{array}{l}\text { Sangat perlu } \\
\text { Perlu } \\
\text { Kurang perlu } \\
\text { Tidak perlu }\end{array}$ & $\begin{array}{r}=4 \\
=10 \\
=1 \\
=1\end{array}$ & $\begin{array}{l}25,00 \% \\
62,50 \% \\
06,26 \% \\
06,26 \%\end{array}$ \\
\hline 5. & $\begin{array}{l}\text { Pendapat peserta didik mengenai peningkatan nilai menulis } \\
\text { teks tanggapan terkait penggunaan media Zoom-meeting }\end{array}$ & $\begin{array}{l}\text { Sangat bisa } \\
\text { Bisa } \\
\text { Tidak bisa }\end{array}$ & $\begin{array}{c}=5 \\
=10 \\
=1\end{array}$ & $\begin{array}{l}33,33 \% \\
62,50 \% \\
06,26 \%\end{array}$ \\
\hline
\end{tabular}

Data pertama adalah angket tentang pembelajaran bahasa Indonesia yang telah berlangsung pengenalan peserta didik tentang materi teks tanggapan, Berikutnya adalah data observasi langsung maupun tidak langsung yang dilakukan selama pembelajaran zoom meeting dan pembelajaran WAG di rumah. Adapun rincian data tersebut antara llain: sebanyak 61,1\% peserta didik mengatakan bahwa menulis teks tanggapan itu sulit, sementara 33,3\% mengatakan mudah; Bagian Kesulitan yang dialami peserta didik dalam menulis teks tanggapan 38\% bagian penilaian, 27\% bagian deskripsi, 22\% kebahasaan dan $11 \%$ bagian struktur teks; Pembelajaran teks tanggapan yang dilakukan dengan WA Group $61 \%$ peserta didik mengatakan sulit dupahami, 38\% lainnya mengatakan mudah dipahami; 
Apakah diperlukan suatu media, teknik atau media khusus untuk pembelajarn teks tanggapan? 61\% menjawab perlu, $27 \%$ menjawab sangat perlu. $12 \%$ lainnya mengatakan kurang perlu; $94 \%$ peserta didik menyatakan penggunaan media, teknik, metode termasuk Zoom meeting dapat meningkatkan hasil menulis teks tanggapan.

Dari data angket terebut dapat dinyatakan bahwa pembelajaran Zoom-meeting membuat peserta didik lebih semangat, termotivasi dan lebih aktif karena adanya interaksi langsung, perhatian langsung, berkomunikasi langsung, tercatat $87,6 \%$ peserta didik berpendapat demikian. Pembelajaran menggunakan media Zoom- meeting membuat pemahaman materi, konsep maupun kemampuan menulis teks tanggapan lebih baik.

Dari keseluruhan data utama dan pendukung dapat dinyatakan bahwaPenelitian Pra-Eksperimen dengan bentuk Intac-group Comparison (membandingkan penggunaan dua media pembelajaran online) diperoleh jawaban atas hipotesis yang menduga bahwa penggunaan Zoom-meeting efektif meningkatkan hasil belajar bahasa Indonesia materi menulis teks tanggapan pada peserta didik kelas IX. SMPN Jakarta.

Hasil Penelitian ini mendukung dua penelitian yang dilakukan sebelumnya yang menyatakan bahwa penggunaan media Zoom Presentation lebih unggul dalam meningkatkan kompetensi mengingat, memahami, menerapkan, dan menganalisis siswa. Hasil penelitian yang senada menyimpulkan bahwa penggunaan media Zoom Cloud meeting mampu meningkatkan level pemahaman mahasiswa. Memang satu penelitian yang dilakukan Danin Haqien, dkk. Menyimpulkan bahwa penggunaan aplikasi Zoommeeting tidak begitu efektif dalam pembelajaran jarak jauh, namun data hasil penelitian menunjukkan $70 \%$ mahasiswa menyatakan efektif.

\section{SIMPULAN DAN SARAN}

Setelah melakukan pembahasan hasil penelitian terkait penggunaan media Zoom-meeting dan media Whatsapp group dalam pembelajaran menulis teks tanggapan, sekaligus menjawab pertanyaan penelitian yang diajukan pada sub topik terdahulu; bahwa pembelajaran dimasa pandemi Covid-19 yang dilakukan tanpa adanya tatap muka dan tanpa interaksi langsung menghadapi banyak kendala.

Menurunnya semangat belajar, menurunnya kreatifitas, munculnya rasa bosan dengan pembelajaran terbatas, menurunnya kedisiplinan, hingga menurunnya hasil belajar peserta didik menjadi suatu yang sangat dimungkinkan.

Penggunaan media Zoom-meeting adalah salah satu jawaban untuk mengembalikan interaksi langsung antara peserta didik dan pendidik sebagai pengganti tatap muka. Interaksi langsung media Zoom dalam pembelajaran terbukti membuat perbedaan hasil belajar yang cukup signifikan antara kelas Zoom-meeting dan kelas Whatsapp. Simpulan penelitian adalah penggunaan Zoom-meeting efektif untuk meningkatkan kemampuan menulis teks tanggapan peserta didik kelas IX. SMPN Jakarta semester genap tahun pelajarn 2020/2021.

Berdasarkan simpulan di atas maka disarankan kepada guru: Penggunaan Zoom-meeting adalah salah satu solusi dari banyak media yang bisa dilakukan untuk meminimalisasi kendala yaitu menggantikan tatap muka yang tidak dimungkinkan pelaksanaannya dimasa pandemi. Zoommeeting membantu guru meningkatkan pemahaman materi dan konsep, menanamkan nilai karakter, memberikan perhatian dan motivasi, menyepakati banyak hal positif dengan peserta didik, dll.

Kreatif menggunakan sumber-sumber belajar sehingga memberi kemudahan pada peserta didik dalam mempelajari pengetahuan, menyediakan materi-materi menarik membuat pembelajaran menyenangkan, memproses generasi berkualitas, serta tidak berhenti belajar memahami penggunan teknologi software (aplikasi-aplikasi) yang mendukung pembelajaran.

Saran untuk siswa agar senantiasa termotivasi dalam mengikuti pembelajaran di masa pandemi Covid 19 dengan kesungguhan; memiliki rasa tanggung jawab untuk menyelesaikan tugas belajar; serta memiliki kebiasaan belajar secara mandiri.

Saran untuk peneliti lain agar melakukan penelitian lebih lanjut mengenai aspek yang belumdikaji lebih mendalam, lebih luas, dan lebih konprehensif dalam penelitian ini. 
Istiqomah, Jurnal Lingkar Mutu Pendidikan, 18 (1), 107-113, Juni 2021

\section{PUSTAKA ACUAN}

Asep Ganda Sadikin, dkk. Bahasa Indonesia untuk SMPIMTs Kelas IX. Bandung: Grafindo Media Pratama, 2019.

Claudya, Bunga Cintya. "kompasiana.com." Kelebihan dan Kelemahan Zoom-meeting sebagai media Pembelajaran Daring, 19 April 2020: 2.

Danin Haqien, Aqillah Afifadiah Rahman. "Pemanfaatan Zoom-meeting untuk proses pembelajaran pada Masa Pandemi Covid 19." SAP (Susunan Artikel Pendidikan), 2020: Vol. 5 No. 1.

Hernowo. Menjadi Guru yang Mau dan Mampu Membuat Buku. Bandung: Mizan Learning Center (MLC), 2006.

Mahsun, Prof. Dr. Pembelajaran Bahasa Indonesia Berbasis Teks. Depok: Raja Grafindo Persada,2018.

Putri Zakiyyatul Zannah, Diah Mulhayatiah Fathiah Alatas. "Penggunaan Media Pembelajaran Zooming Presentation untuk Meningkatkan Hasil BelajarPeserta Didik Kela X pada Konsep Suhu dan Kalor di SMAN Tangerang Selatan." Jurnal Pendidikan www.media neliti.com, 2014: Vol. 3 No. 1.

Raditya Eka Putri, dan kawan-kawan. "Pemanfaatan Aplikasi Zoom Cloud Meeting sebagai Media E-Learning dalam Mencapai Pemahaman Mahasiswa di Tengah Pandemi Covid 19." Jurnal Common, Desember 2020: Volume 4 No 2.

Al, Kementrian Pendidikan dan Kebudayaan. Materi Pelatihan Guru Implementasi Kurikulum 2013 SMP Pelajaran Bahasa Indonesia. Jakarta: Kementrian Pendidikandan Kebudayaan, 2016.

Tarigan, Henry Guntur. Menulis sebagai Sebuah Keterampilan Berbahasa. Bandung: Angkasa,1985. 